\title{
Incremental-dose effects of atropine on photic afterdischarge
}

\author{
RICHARD H. ANDERSON, DONOVAN E. FLEMING, \\ MICHAEL ALBERTS, and BRIAN C. ROBERTS \\ Brigham Young University, Provo, Utah
}

\begin{abstract}
Photically evoked afterdischarges (PhAD) recorded from the visual cortex are thalamically coupled hypersynchronous patterns known to be sensitive to changes in level of behavioral arousal. In the present study, parameters of $\mathrm{PhAD}$ patterns were examined in lightly restrained rats following incremental injections of various dosages of atropine sulfate. Low doses of atropine increased PhAD occurrence, whereas high doses of atropine suppressed the elicitation of this pattern as compared to saline- and methyl-atropine-treated control animals. A low level of atropine is hypothesized to reduce or stabilize reticular activation of thalamic and cortical neuron pools, thus generating a level of excitation compatible with pronounced PhAD elicitation. Conversely, asynchronous electrocortical patterns produced by high levels of atropine are associated with a physiological substrate that precludes the development of hypersynchronous PhAD bursts.
\end{abstract}

A single photic stimulus delivered to the visual system of the rat elicits an evoked cortical potential which is followed by a series of hypersynchronous, thalamically paced waves, coupled with the visual evoked response (VER). Termed photic afterdischarge (PhAD), this electrocortical pattern is thought to be generated by the lateral geniculate nucleus (LGN) of the thalamus and is modulated by various limbic, brainstem, and thalamic systems (Shearer \& Creel, 1978).

In a number of studies, Fleming and collaborators (Fleming, Shearer, \& Creel, 1974; Standage \& Fleming, 1977,1978 ) have shown that $\mathrm{PhAD}$ parameters can serve as sensitive indices of both behavioral and pharmacological arousal. Central nervous system (CNS) stimulants such as amphetamine and pilocarpine reliably suppress the percentage of occurrence of PhAD in a dose-response manner; behavioral arousal during habituation of a legflexion response similarly suppresses $\mathrm{PhAD}$ parameters (Standage \& Fleming, 1977).

Previous research has suggested that the relationship between PhAD production and arousal is at least partly mediated by cholinergic systems. Bigler and Fleming (1976) have shown that cholinergic excitation by physostigmine produces a low-voltage fast cortical electroencephalogram (EEG) and suppresses PhAD. As cholinergic ascending systems innervate the LGN and cortical laminae (Krnjevic, 1974; Nakai \& Takaori, 1974), it seems plausible that excitation of these cholinergic pathways could interrupt thalamocortically paced PhAD production. However, atropine sulfate has been shown to have a suppressive effect on $\mathrm{PhAD}$ generation when administered systematically in large dosages $(6 \mathrm{mg} / \mathrm{kg})$

Send reprint requests to Richard H. Anderson, St. Louis University School of Medicine, 1402 South Grand Blvd., St. Louis, MO 63104.
(Bigler \& Fleming, 1976). This was surprising, as atropine simultaneously induced large-amplitude, irregular slowwaves (LIA) in the hippocampus, a pattern previously considered to be a concomitant of $\mathrm{PhAD}$ production (Bigler \& Fleming, 1976).

Nevertheless, the marked effects of physostigmine and atropine on both PhAD and cortical EEG suggest that PhAD and cortical arousal are linked cholinergically. The present study was thus designed to investigate further the effects of atropine on $\mathrm{PhAD}$ production. It was expected that a clearer picture of the effect of atropine at both high and low dosages would be helpful in evaluating the importance of ascending cholinergic pathways for PhAD production.

\section{METHOD}

\section{Subjects}

Five Sprague-Dawley rats, $180-200$ days old, were surgically prepared with indwelling stainless-steel-screw electrodes implanted over the right and left visual cortices at points $6 \mathrm{~mm}$ posterier to bregma and $3 \mathrm{~mm}$ lateral to the midline. A reference electrode was implanted over the cerebellum, and all electrodes were attached to a Plastic Products female receptacle which was cemented to the skull with dental acrylic resin. At least 7 days of recovery were allowed before any treatment sessions were initiated. All experiments were carried out with waking animals with mydriatic pupils ( $2 \%$ ophthalmic atropine sulfate).

\footnotetext{
Apparatus and Procedure

Subjects were held under light restraint in a suspended hammock which was positioned to directly face a Grass Model PS22 photostimulator lamp at a distance of $35 \mathrm{~cm}$. A translucent plexiglass hemicylinder was placed between the animal and the lamp to diffuse the light. The photostimulator was programmed to deliver $10-\mu \mathrm{sec}$ light pulses at a rate of $1 / 4 \mathrm{sec}$; the animal and apparatus were enclosed within a shielded and darkened room. Brain responses were amplified with Grass P15 ac preamplifiers and displayed on a Tektronix R5103 oscilloscope for monitoring. Responses were recorded on magnetic tape on a Tektronix 564B storage oscilloscope for later playback for analysis.
} 
Following recovery from surgery, a rat was placed in the restraining hammock and injected with one of the following drugs at the levels specified: atropine sulfate, $0.3 \mathrm{mg} / \mathrm{kg}$ (Treatment $\mathrm{A}$ ); atropine sulfate, $1.5 \mathrm{mg} / \mathrm{kg}$ (Treatment B); atropine sulfate, $3.0 \mathrm{mg} / \mathrm{kg}$ (Treatment C); atropine methyl nitrate. $6.0 \mathrm{mg} / \mathrm{kg}$ (Treatment D); or physiological saline (Treatment E). Both saline and methyl atropine served as controls. During experimental sessions, each drug was injected subcutaneously in equal-volume amounts according to a previously determined random schedule. Fifteen min following the first injection, iterative photic stimulation was initiated at a frequency of $1 / 4 \mathrm{sec}$ and continued until 100 flashes had been presented $(7 \mathrm{~min})$. At this time the recorder was stopped, and a second injection of the same drug was administered and another 15-min acclimation period allowed to elapse, after which 100 more photic stimuli were presented and responses recorded. This procedure was repeated once more. Approximately 70 min were required per individual drug session. A minimum of 4 days was allowed to elapse between each drug session.

\section{Measurement and Statistical Analysis}

Photic afterdischarges from the right visual cortex were analyzed. Two measures of PhAD activity were taken: (1) percentage of occurrence of PhAD activity, with a scorable burst defined operationally as a minimum of two sinusoidal waves developing after the third negative wave (N3) of the visual evoked response, and having at least twice the amplitude of N3; (2) the number of spindle waves per PhAD burst. Both percentage of occurrence and number of spindle waves per PhAD burst were analyzed separately for each injection block of 100 photic stimuli presented at each drug level.

Individual data were summed across subjects for each block, and means were calculated for both percentage of occurrence and number of spindles per burst. For percentage of PhAD occurrence, analysis of variance and multiple comparison tests (Scheffé and LSD) were used to determine significant variance between drug levels and injection levels. Medians of the number of spindle bursts were correlated with percentage of occurrence across each drug and injection level, using Pearson's product-moment correlation coefficient.

\section{RESULTS}

During control periods, all animals displayed fully elaborated PhAD patterns (see Figure 1 for a representative wave). Means for percentage of occurrence of

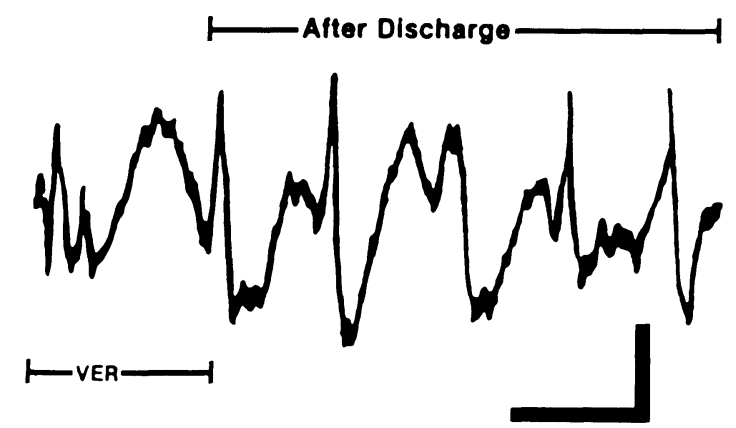

Figure 1. A representative example of a well-elaborated VER with PhAD, showing both spike and wave components. Negativity is an upward deflection. Horizontal calibration represents 200 msec; vertical calibration represents $200 \mu \mathrm{V}$.

PhAD for dosage and increment level are summarized in Table 1. Analysis of the column means (injection-level main effect) indicated that PhAD bursting was significantly suppressed following Injection $3(F=13.38$, $\mathrm{df}=2 / 8, \mathrm{p}<.003)$. Examination of Table 1 indicates that after Injection 3, both Treatments $B$ and $C$ produced an attenuation of PhAD bursting. Analysis of the row means (dosage) indicated that the treatment main effects were masked by increment level $(\mathrm{F}=0.67, \mathrm{df}=4 / 16$, $p>.50)$. This observation was confirmed by a significant dosage $\times$ increment level interaction $(F=12.35$, df $=8 / 32, p<.0001)$.

Pairwise comparisons (Scheffé and LSD tests) revealed that Treatments A2, B3, C2, and C3 (see Table 1) could be differentiated from other control and atropine treatments. Note that the control treatments did not vary significantly with repeated injections (saline, $\mathrm{p}>.70$; atropine methyl nitrate, $p>90$ ). From Table 1 , it is seen that two injections of atropine sulfate at the low dosage

Table 1

Mean Percentage ( \pm SEM) of Afterdischarge Bursting Differences Within Dosages by Incremental Injection Levels

\begin{tabular}{|c|c|c|c|c|}
\hline \multirow[b]{2}{*}{ Dosage } & \multicolumn{4}{|c|}{ Injection Level } \\
\hline & 1 & 2 & 3 & Row Mean \\
\hline $\begin{array}{l}\text { A. } 0.30 \mathrm{mg} / \\
\mathrm{kg} \\
\text { Atropine } \\
\text { Sulfate }\end{array}$ & $53.8 \pm 2.3$ & $70.2 \pm 1.7 *$ & $67.0 \pm 1.3$ & 63.7 \\
\hline $\begin{array}{l}\text { B. } 1.5 \mathrm{mg} / \mathrm{kg} \\
\text { Atropine } \\
\text { Sulfate }\end{array}$ & $69.4 \pm 4.5$ & $60.2 \pm 1.2$ & $26.2 \pm 4.2 * \dagger$ & 95.1 \\
\hline $\begin{array}{l}\text { C. } 3.0 \mathrm{mg} / \mathrm{kg} \\
\text { Atropine } \\
\text { Sulfate }\end{array}$ & $69.8 \pm 4.8$ & $58.0 \pm 4.7 \ddagger$ & $30.2 \pm 3.7^{* \dagger}$ & 52.7 \\
\hline $\begin{array}{l}\text { D. } 6.0 \mathrm{mg} / \mathrm{kg} \\
\text { Methyl } \\
\text { Atropine }\end{array}$ & $65.0 \pm 2.6$ & $66.0 \pm 2.1$ & $59.6 \pm 2.9$ & 63.5 \\
\hline E. Saline & $60.8 \pm 5.4$ & $59.6 \pm 3.9$ & $52.6 \pm 3.7$ & 57.7 \\
\hline Column Mean & 63.8 & 62.8 & 47.1 & \\
\hline
\end{tabular}

*Different from Injection 1 at .01 level; $†$ Different from Injection 2 at .01 level; $\ddagger D i f f e r e n t$ from Injection 1 at .05 level. 
of $0.30 \mathrm{mg} / \mathrm{kg}$ (A2) increased the occurrence of PhAD, whereas a third injection at this dosage (A3) had no further effect. Conversely, a third injection of atropine at the intermediate $1.5 \mathrm{mg} / \mathrm{kg}$ dosage (B3) suppressed $\mathrm{PhAD}$. At the high dosage, $3.0 \mathrm{mg} / \mathrm{kg}$, a second injection was sufficient to suppress PhAD (C2), and the third $3.0-\mathrm{mg} / \mathrm{kg}$-injection was sufficient to suppress $\mathrm{PhAD}$ (C2), and the third 3.0-mg/kg-injection (C3) suppressed the percentage of $\mathrm{PhAD}$ still further.

Table 2 gives the median number of spindle waves per PhAD burst at each treatment level. Spindle frequency was defined as the number of negative waves past N3 of the VER at least double the amplitude of the baseline. Pearson's product-moment correlation coefficient showed that the median number of spindles per treatment level correlated positively with the percentage of occurrence of $\mathrm{PhAD}$ at that treatment level $(\mathrm{r}=.68, \mathrm{p}<.01)$.

\section{DISCUSSION}

The present results confirm that atropine has a dose-response effect on PhAD production. Our results extend earlier findings in two directions: (1) atropine suppresses PhAD in dosages as low as two incremental injections of $1.5 \mathrm{mg} / \mathrm{kg}$, and (2) dosages at or below $1.5 \mathrm{mg} / \mathrm{kg}$ increase rather than suppress PhAD. The relatively strong positive correlation between percentage of occurrence of $\mathrm{PhAD}$ and number of spindle waves per burst supports an earlier conclusion of Bigler and Fleming (1976) that these two PhAD parameters are closely related.

At the behavioral level, PhAD occurs most reliably during a state of relaxed wakefulness (Sumitomo \& Klingberg, 1972). PhAD elicitation is suppressed in behaviorally aroused animals which display a low-voltage fast cortical EEG (Shearer \& Creel, 1978). Pharmacologically, CNS stimulants physostigmine and amphetamine increase reticular activation and suppress $\mathrm{PhAD}$ production; diazepam, on the other hand, which decreases reticular activation, also suppresses $\mathrm{PhAD}$ when administered in dosages in excess of $2.0 \mathrm{mg} / \mathrm{kg}$ (Bigler \& Eidelberg, 1976). Evidently, for PhAD to occur, reticular excitation of the thalamus must be stabilized at a relatively low level.

It would be predicted that atropine, by inhibiting cholinergic excitation, could have such a modulating effect on reticular activation. Our

Table 2

Medians of Frequencies of Positive Spikes per PhAD Burst ( \pm SEM)

\begin{tabular}{|c|c|c|c|c|}
\hline \multirow[b]{2}{*}{ Dosage } & \multicolumn{4}{|c|}{ Injection Level } \\
\hline & 1 & 2 & 3 & Row Mean \\
\hline $\begin{array}{l}\text { A. } 0.30 \mathrm{mg} / \mathrm{kg} \\
\text { Atropine } \\
\text { Sulfate }\end{array}$ & $4.5 \pm .02$ & $4.0 \pm .04$ & $3.9 \pm .02$ & 4.1 \\
\hline $\begin{array}{l}\text { B. } 1.5 \mathrm{mg} / \mathrm{kg} \\
\text { Atropine } \\
\text { Sulfate }\end{array}$ & $5.0 \pm .03$ & $3.7 \pm .02$ & $3.4 \pm .04$ & 4.0 \\
\hline $\begin{array}{l}\text { C. } 3.0 \mathrm{mg} / \mathrm{kg} \\
\text { Atropine } \\
\text { Sulfate }\end{array}$ & $4.8 \pm .01$ & $4.7 \pm .04$ & $3.4 \pm .02$ & 4.0 \\
\hline $\begin{array}{l}\text { D. } 6.0 \mathrm{mg} / \mathrm{kg} \\
\text { Methyl } \\
\text { Atropine }\end{array}$ & $4.4 \pm .02$ & $4.4 \pm .03$ & $4.5 \pm .03$ & 4.4 \\
\hline E. Saline & $4.5 \pm .04$ & $4.6 \pm .02$ & $4.2 \pm .04$ & 4.4 \\
\hline Column Mean & 4.6 & 4.1 & 3.9 & \\
\hline
\end{tabular}

results substantiate this prediction at the $0.30 \mathrm{mg} / \mathrm{kg}$ dosage level, indicating that low doses of atropine increase $\mathrm{PhAD}$ production above baseline control levels. Presumably this increase in PhAD following low doses of atropine reflects a movement toward a level of arousal compatible with optimum $\mathrm{PhAD}$ production.

Bradley (1958) reported that at high atropine dosages $(1-3 \mathrm{mg} / \mathrm{kg})$, waking animals display an irregular, large-amplitude EEG during periods of behavioral arousal and during mesencephalic reticular stimulation. It is reasonable to assume that such an electrically dissociated cortex would be unresponsive to thalamically generated electrical patterns. The asynchronous cortical EEG produced by high atropine levels bears a strong resemblance to the large-amplitude, irregular EEG of deep sleep, and in fact PhAD is not elicited during deep sleep or deep anesthesia (Shearer \& Creel, 1978). It seems likely that high atropine levels suppress the cholinergic modulation of a broad range of cortical neurons, thereby depressing their responsivity to synchronous thalamocortical input. The asynchronous electrical patterns at the cortex associated with high atropine levels are thus not compatible with PhAD production.

In conclusion, the augmentation and suppression of $\mathrm{PhAD}$ by atropine at different dosage levels can be explained by separate mechanisms, both linked to cholinergic, ascending reticular pathways. In the case of PhAD augmentation, atropine blockade of cholinergic synapses stabilizes reticular excitation of thalamic neurons, facilitating PhAD production. PhAD suppression by higher atropine dosages appears to occur at a cortical level, the result of a masking effect by a dissociated cortical EEG.

\section{REFERENCES}

Bigler, E. D., \& Eidelberg, E. (1976). Diazepam suppression of evoked after-discharges in rat lateral geniculate nucleus and visual cortex. Proceedings of the Western Pharmacological Society, 19, 435-438.

Bigler, E. D., \& Fleming, D. E. (1976). Pharmacological suppression of photically evoked after-discharges in rats: Incremental dose, hippocampal EEG and behavioral activity correlates. Psychopharmacology, 46, 73-82.

BradLEY, P. B. (1958). The central action of certain drugs in relation to the reticular formation of the brain. In H. H. Jasper, L. D. Proctor, R. S. Knighton, W. C. Noshay, \& R. T. Costello (Eds.), Reticular formation of the brain. Boston: Little, Brown.

Fleming, D. E., Shearer, D. E., \& Creel, D. J. (1974). Effect of pharmacologically-induced arousal on the evoked potential in the unanesthetized rat. Pharmacology, Biochemistry \& Behavior, 2, 187-192.

KRNJEVIC, K. (1974). Chemical nature of synaptic transmission in vertebrates. Physiological Review, 54, 418-540.

NAKAI, Y., \& TAKAORI, S. (1974). Influence of norepinephrinecontaining neurons derived from the locus coerulus on lateral geniculate neuronal activities of cats. Brain Research, 71, 47-60.

Shearer, D. E., \& Creel, D. (1978). The photically evoked afterdischarge: Current concepts and potential applications. Physiological Psychology, 6(3), 369-376.

Standage, G. P., \& Fleming, D. E. (1977). Photic after-discharge bursting during habituation of a leg flexion response. Physiology \& Behavior, 20, 411-415.

Standage, G. P., \& Fleming, D. E. (1978). Visual cortical hypersynchronous bursting as an index of shifts in behavioral state. Physiology \& Behavior, 23, 35-38.

Sumitomo, I., \& KLingBerg, F. (1972). The role of the lateral geniculate body in the generation of photically and electrically evoked afterdischarges in free moving rats. Acta Biologica et Medica Germanica, 29, 43-54.

(Manuscript received for publication August 13, 1985.) 